Foundations of Thoracic Surgery

F. Ronald Edwards. Pp. vii +180 , illustrated. Edinburgh and London: E. \& S. Livingstone. 1966. 50 s.

This stimulating book by Mr. Ronald Edwards is a collection of expanded lectures and demonstrations on thoracic surgery, and represents the current practice in the Liverpool Cardio-Thoracic Centre. It is written in note form making extensive use of excellent diagrams. Many well reproduced radiographs are shown and together with the diagrams of the subject concerned are so arranged as to be in immediate relationship to the text. Any remarks concerning details of this book are more in the nature of differences of opinion rather than of criticism

It is reasonable to prefer the steep head down position to the use of endobronchial cuffs or balloons when performing lobectomy for bronchiectasis, (p. 48) but for children the sitting position may be even safer in preventing a spillover, transfusion maintaining the blood pressure in this position. No mention is made of periostitis occurring in several adjacent ribs in the early stages of a pleuro-pulmonary infection as being the only radiographic appearance diagnostic of thoracic actinomycosis (p. 51).

Tracheal cylindroma (p. 59) may present as several tumours of multicentric origin when radiotherapy gives better results than excision.

When a tracheostomy tube needs changing (p. 82) it makes it much easier for the nursing staff if a Bjork type of tracheostomy has been performed.

The sections on congenital and acquired heart disease are particularly good and the diagrams most informative. In discussing the surgical treatment of aortic stenosis (p. 125) it is very doubtful if blind aortic valvotomy is now ever indicated, except where aortic and mitral stenosis co-exist, when blind valvotomy on both valves must be performed at the same operation.

When describing cardiac massage through the open chest (p. 142) emphasis should be placed on the correct method of performing this for the benefit of the uninitiated who may be tempted to squeeze the ventricles between thumb and fingers, with the resulting danger of ventricular perforation. In children the heart should be compressed between the flattened fingers and the back of the sternum, and in adults between the flat of two hands.

While stressing the excellent results obtained with Heller's operation for the treatment of achalasia of the cardia (p. 157) bouginage and hydrostatic bag treatment are also mentioned, but should at the same time have been condemned as perforation may result from their use.

It is stated that an E.C.G. should be taken to differentiate between the pain of coronary ischaemia and hiatus hernia, but the patterns unfortunately may be identical, and after repair of a hiatus hernia, an "ischaemic" E.C.G. pattern can quickly return to normal.

This book cannot be too highly praised and should be read by all housemen and registrars on Thoracic Surgical Units and by all who are reading for higher surgical qualifications.

\section{Neurogenic Hypertension}

C. J. Dickinson. Pp. xiii +274 illustrated. Oxford:

Blackwell Scientific Publications. 1965. 52s. 6d.

In the introduction, the author proposes the hypothesis that resistance to the blood flow through the brain, especially the medulla, is an important long-term influence upon the systemic arterial pressure. The book consists of a critical analysis of this hypothesis, and is, therefore, "virtually a scientific autobiography, and those $>$ who dislike autobiographies will dislike this one."

The book is in three sections. The first part describes $c$ the development of the hypothesis, and its materialism over a number of years: In the second part the hypothesis is tested and all the supporting evidence reviewed $\overrightarrow{+}$ in great detail and critically evaluated. On this theory, Essential Hypertension is the result of failure to compen- $\overline{\bar{G}}$ sate for increased cerebrovascular resistance, due largely $\bar{c}$ to atheroma involving the larger arteries supplying the $\mathbb{D}$ hind-brain. Similarly, renal hypertension could show the same vascular cause. Obviously the atheroma could os equally be the result, rather the cause, of the raised $\vec{\theta}$ pressure.

The final section of the book is an extension of the $\vec{\overrightarrow{ }}$ hypothesis and its practical applications, including the $\omega$ novel suggestion that angiography of the vessels of the hind-brain be used to determine whether or not a patient $\subseteq$ O has essential hypertension, as distinct from renal or 3 adrenal causes.

It is obviously easy to be sceptical or any work proposing a new hypothesis of disease. This book is the $\vec{c}$ outcome of immense thought and work, is beautifully $\omega$ written, full of excitement and stimulation and recommended to all interested in the problem of raised blood $\omega$ pressure.

\section{The Small Intestine}

Symposium of the 5th Congress of the International $z$ Academy of Pathology. Edited by A. C. THACKRAY and F. A. Jones. Pp. 132, illustrated. Oxford: Blackwell Scientific Publications. 1966. 22s. 6d. ए In June, 1964 a symposium on the small intestine was $\mathbb{D}$ held during the meeting of the International Acaden of Pathology in London. This slim paperback contain $\overrightarrow{6}$ the papers given at the symposium by a formidabere gathering of authors. One's initial emotion is one of regret - at not being there. This book titillates but does not satisfy - illustration, other than line graphs and line drawings, are absent; this lack is particularly crippling in the articles dealing with electron microscopy and mucosal appearances of the small intestine, and with the radiological approach to diagnosis. Moreover, three $\varrho$ contributions are not accompanied by references.

Nevertheless the symposium, and this book are successful. Fourteen chapters include accounts of the deformities of the intestine, histo-chemistry of the jejunum; mucosal and radiological features of various? intestinal diseases, and excellent contributions on the intestinal aspects of shock. Whipple's disease, Crohn's disease and carcinoid tumours are reviewed.

The booklet will provide those who attended the conference with a permanent record of its activities the rest of us can only regret that a complete monograph $\delta$ on the structure and function of the small intestine is still to be written.

\section{Nervous Control of the Heart}

Edited by Walter C. Randall. Pp. xx +251 , illustrated. Baltimore: Williams and Wilkins. $\mathrm{N}$ Edinburgh and London: E. \& S. Livingstone. 1965. o 90s.

The advent of B adrenergic blocking drugs for clinical $\mathrm{N}$ use has greatly stimulated interest in the nervous control $\omega$ of the heart. This wonderful book is based on a symposium in which several leading investigators and teams in the United States presented their work, ideas and hypotheses.

As might have been expected from the sophistication? of present day haemodynamic techniques, the largest section of the book is that of Sarnoff and associates. 
A great deal of experimental work is reviewed - much of it very elegant work. The discussion ranges as far afield as coupled pacing and the atrial contribution to closure of the mitral valve. Each idea and proposition has been tested experimentally and the authors finally integrate all the effects of sympathetic and vagal stimulation.

The sections of the book dealing with the role of the central nervous system are necessarily more philosophical and the experimental evidence less clearcut and more difficult to interpret. There is an informative section on the terminal innervation of the heart - a subject which has been neglected in the past.

This is an extremely valuable book. So much information is presented that it can be read again with advantage. The symposium took place in 1963, only a few days before the death of Carl J. Wiggers, who was to have attended it. The dedication of this important and exciting book to Dr. Wiggers seems appropriate and pleasing.

\section{Psychosomatic Disorders in Adolescents and Young Adults}

Edited by J. Hambling and Philip Hopkins. Pp. 246. Oxford and London: Pergamon Press. 1965. 60s.

This volume is the belatedly published edited Proceedings of the 1960 Conference of the Society for Psychosomatic Research. However, very few of the papers have to do with changing fashions of medicine and the delay in publication has not affected their value for the reader. The standard of the papers varies considerably and there are some poor ones. Some of them deal with specific illnesses and behaviour patterns in adolescence such as acne, appendicitis, tonsillitis, epilepsy, diabetes mellitus, tuberculosis, sexual behaviour and pregnancy. Too many of these papers are concerned only with the impact of the illness on the adolescent personality. However, the paper by Hambling on the relationship of infectious illness to stress is more penetrating. Two good papers deal with the adolescent in industry and university respectively. Others are concerned with concepts concerning the nature of adolescence and in these sections there are excellent papers by people such as Ilse Hellman, Winnicott, Dicks, Wisdom and others who succinctly and sometimes provocatively distil the essence of their years of clinical experience. The price of the book is high.

\section{NEW EDITIONS}

\section{Hormone Assays and their Clinical Applications}

J. A. LoRAINE and E. T. Bell. 2nd edition. Pp. $x v+$ 584, illustrated. Edinburgh and London: E. \& S. Livingstone. 1966. 65s.

The first edition of this book enjoys a high reputation, and this second edition lives up to its predecessor. As the preface says, a great expansion has taken place in endocrinology over the last eight years, with the development of accurate and precise methods of assay for many hormones, and this edition concentrates mainly on work published between 1958 and 1965 . The documentation of the evidence is painstaking and exhaustive.

The first chapter dealing with the principles underlying hormone assay is admirable, being at the same time detailed and understandable. No mathematical or statistical methods are included, but the reader is directed to the relevant papers. This section should be read by everyone about to undertake an investigation involving hormone assay.
The endocrine glands to which most attention is paid are the anterior pituitary gland, the adrenal cortex and the ovary. It seems a pity that the book was not made more complete by sections on the thyroid and the posterior pituitary gland.

Two extra chapters are included in this edition on the hormonal interrelationships in health and disease which will be of great interest to all who are concerned with the application of hormone assays to clinical problems. The first deals with hormonal interrelationships in gynaecological disorders and pregnancy, whilst the second deals with the effect of various synthetic compounds on pituitary and ovarian function in women.

Chemical and immunological methods are rapidly replacing biological methods, but it is a sobering thought that most of the techniques which are described in this book are outside the scope of the routine clinical laboratory and are likely to remain so for some time to come.

\section{Anatomy of the Human Body}

R. D. Lockhart, G. F. HAmilton and F. W. Fyfe.

Second Edition. Pp. ix +697 , illustrated. London:

Faber and Faber. 1966. £6 6s.

Modern anatomists, as compared to those of the classical age, have been likened to a flock of geese entering a field after the crops have been gathered in, making more noise over the few ears of corn left behind than the original reapers made over the whole harvest. The advent of a second edition of what is still a new book might tempt the cynic to ask what is new in anatomy? The answer is that new discoveries are being made in the anatomy of the central nervous system, but what is more important is a new and more imaginative approach to teaching and it is this aspect of modern trends that is attempted in the book under review.

The authors set out to write a book on systemic? anatomy, but emphasise in the introduction the place of dissection and regional anatomy in the overall study of the subject. The book has been kept to a reasonable size, and the use of illustrations and pictures is made use of to the full. The picture on the cover, reminiscent of Vesalius and Leonardo da Vinci, shows that the aim of the authors is to teach the anatomy of the living body. It is, therefore, pleasant to see surface anatomy promoted from an obscure last chapter to its place as an integral part of the study so that the student learns to see and feel the underlying anatomy of the patient.

The chapter on muscles is an attempt to correlate structure and function, which would have gladdened the heart of John Hunter because the muscles really do appear to live and move and have their being, and this section is of value not only to the student but to the practitioner and physiotherapist as well.

The chapter on the central nervous system was examined eagerly to see if those student bugbears, the brachial plexes, the petrosal nerves, and the rhinencephalon, have been lifted as by magic from the levels of blood and toil to the heights of subliminal advertising, but no; the way is still hard but the pictures make it easier. Those who lack a retentive memory often find that correlation of facts counteracts the ravages of amnesia. The academic anatomists turn to comparative anatomy, whilst the student of medicine turns to clinical application. Here, this book gains first marks, the pictures on pages 287-294 are of value to both the pre-clinical student and the clinician.

This is an imaginative book, not too big, well illumined by pictures, of value to the student and the clinician, a successful attempt at a text-book of anatomy for the modern age. 